\title{
HASIL PERANCANGAN MODUL KALKULUS DASAR DAN LANJUT DENGAN MENGGUNAKAN MAPLE 14
}

\author{
Isra Nurmai Yenti \\ Jurusan Tadris Matematika Fakultas Tarbiyah IAIN Batusangkar \\ Korespondensi: Jln. Sudirman No. 137 Kubu Rajo Lima Kaum Batusangkar \\ e-mail: nurmaiyenti@yahoo.com
}

\begin{abstract}
This research aims at producing the module design of basic and advanced calculus using Maple 14 in mathematics computer application course. This research used research and development. The module was developed by modifying the previous module as designed by Rahman (2013). The stages applied refers to Akker and Plom (1994). The module consists of three units introduction, learning activities, and closing. Based on the findings, this module could be used in teaching mathematics computer application subject.
\end{abstract}

Kata Kunci: modul, Maple 14, kalkulus dasar dan lanjut.

\section{PENDAHULUAN}

$\mathrm{M}$

aple merupakan software matematika buatan Waterloo Maple Inc. dengan kemampuan kerja yang cukup handal untuk menangani berbagai komputasi analitis dan numeric (Marjunis, 2007: 5). Maple dapat digunakan sebagai alat bantu untuk mengajarkan konsep aljabar dan kalkulus. Di STAIN Batusangkar, Maple baru dipakai pada konsep kalkulus.

Maple dapat digunakan untuk semua materi kalkulus dasar dan lanjut. Untuk kalkulus dasar berupa materi menentukan turunan dan integral suatu fungsi, mahasiswa dapat mencek jawaban turunan dan integral suatu fungsi dengan menggunakan Maple. Ketika prosedur penyelesaian turunan atau integral suatu fungsi sangat panjang, kemungkinan mahasiswa melakukan kesalahan sangat rentan sehingga dengan bantuan Maple hal tersebut dapat teratasi. Sebagaimana pendapat Marjunis (2007: 6) yaitu "Penulisan, perhitungan, dan manipulasi ekspresi matematis maupun penanganan grafik 2D, 3D dan animasi dapat dilakukan dengan menggunakan perintah-perintah dengan sintaks yang mudah serta menampilkan respon solusinya sebagaimana yang diperoleh apabila dikerjakan secara manual"

Materi Maple yang sudah diberikan pada perkuliahan aplikasi komputer matematika merupakan materi kalkulus lanjut. Berdasarkan hasil penelitian Yenti (2010), mahasiswa berkesulitan memahami grafik di ruang dimensi tiga. Salah satu produk untuk memudahkan mahasiswa adalah dengan mengerjakan Maple Worksheet. Walaupun produk ini dirancang untuk mahasiswa yang awam dengan Maple, namun saran penelitian ini adalah mahasiswa sudah mengenal dan memahami tentang Maple.

Berdasarkan paparan di atas, terlihat bahwa Maple merupakan alat bantu untuk lebih mendalami materi kalkulus dasar dan lanjut. Namun, karena keterbatasan jumlah pertemuan 
perkuliahan aplikasi komputer matematika untuk materi Maple, modul sebagai salah satu sumber belajar mandiri sangat dibutuhkan dalam perkuliahan ini.

Akan tetapi, modul yang sangat diharapkan oleh mahasiswa untuk belajar mandiri belum ada. Sumber belajar lain berupa buku tentang Maple ini juga terbatas jumlahnya di perpustakaan STAIN Batusangkar. Jika dilihat isi buku tersebut, bahasa yang dipakai belum komunikatif sehingga mahasiswa susah mempelajari materi ini sendiri. Disamping itu, materi pada buku sumber ini masih menggunakan Maple untuk versi 10. Padahal Maple 10 tidak mendukung Windows 7 yang sekarang banyak digunakan mahasiswa.

Berdasarkan permasalahan di atas, perlu dilakukan pengembangan suatu modul Maple untuk kalkulus dasar dan lanjut. Modul ini dirancang dengan memodifikasi format modul yang dikemukakan oleh Rahman. Selanjutnya modul tersebut dikembangkan untuk beberapa kegiatan belajar.

\section{KAJIAN TEORI}

\section{Modul}

Modul merupakan salah satu bentuk bahan ajar yang dikemas secara utuh dan sistematis, didalamnya memuat seperangkat pengalaman belajar yang terencana dan didesaian untuk membantu peserta didik menguasai belajar yang spesifik (Daryanto, 2013: 9). Prastowo (2012: 106) mengemukakan modul adalah sebuah bahan ajar yang disusun secara sistematis dengan bahasa yang mudah dipahami oleh peserta didik sesuai tingkat pengetahuan dan usia mereka, agar mereka dapat belajar sendiri (mandiri) dengan bantuan atau bimbingan yang minimal dari pendidik. Berdasarkan pendapat di atas, dapat disimpulkan bahwa modul adalah bahan ajar mandiri yang tersusun secara sistematis dengan bahasa yang mudah dipahami oleh peserta didik.

Karakteristik modul menurut Rahman (2013: 93) adalah sebagai berikut:

1. Dirancang untuk sistem pembelajaran mandiri

2. Program pembelajaran yang utuh dan sistematis

3. Mengandung tujuan, bahan/kegiatan dan evaluasi.

4. Disajikan secara komunikatif, dua arah.

5. Diupayakan agar dapat mengganti beberapa peran pengajar.

6. Cakupan bahasan terfokus dan terukur.

7. Mementingkan aktivitas belajar pemakai.

Dengan demikian, modul yang dirancang harus memenuhi karakteristik di atas agar dapat digunakan secara mandiri oleh peserta didik. Akhirnya, tujuan akhir dari penggunaan modul dapat tercapai.

Majid (2006:176) menyatakan modul adalah sebuah buku yang ditulis dengan tujuan agar peserta didik dapat belajar secara mandiri tanpa atau dengan bimbingan guru, sehingga modul berisi paling tidak tentang segala komponen dasar bahan ajar yang telah disebutkan sebelumnya, yaitu: 1) Petunjuk belajar, 2) Kompetensi yang akan dicapai, 3) Informasi pendukung, 4) Latihan, 5) Petunjuk Kerja, dan 6) Evaluasi. Sementara itu, format modul menurut Rahman (2013: 94) adalah sebagai berikut:

1. Pendahuluan memuat tujuan, pengenalan terhadap topik yang akan dipelajari, informasi tentang pelajaran, hasil belajar dan orientasi.

2. Kegiatan belajar meliputi Kegiatan belajar 1: Judul
a. Tujuan
b. Materi pokok
c. Uraian materi berisi penjelasan, contoh, ilustrasi, aktivitas, tu- 
gas/latihan, rangkuman

d. Tes mandiri

Kegiatan belajar 2: Judul, struktur seperti kegiatan belajar 1 .

3. Penutup

a. Salam, rangkuman, aplikasi, tindak lanjut, kaitan dengan modul berikutnya

b. Daftar kata penting

c. Daftar pustaka

d. Kunci tes mandiri

Modul yang dirancang mengikuti modifikasi format yang dikemukakan oleh Rahman. Hasil modifikasinya adalah pendahuluan memuat petunjuk penggunaan modul, peta konsep materi, deskripsi materi, dan learning outcomes; kegiatan belajar meliputi tujuan pembelajaran, materi pokok, uraian materi berisi penjelasan, contoh, ilustrasi, aktivitas, latihan, rangkuman, tes mandiri, serta indikator keberhasilan; dan penutup memuat glossary, sumber bacaan, dan kunci tes mandiri.

\section{Maple}

Maple merupakan salah satu software matematika yang banyak beredar di pasaran, selain Matlab, MathCad, Microsoft Math, dan sebagainya. Char (1992: v) menyatakan "Maple is a system for mathematical computation-symbolic, numeric, and graphical. Maple's hundreds of built-in mathematical commands are the product of a decade-long, on-going research project centerd at the University of Waterloo and ETH Zurich". Hal senada juga diungkapkan oleh Marjunis (2007: 5) yaitu maple merupakan software matematika buatan Waterloo Maple Inc. dengan kemampuan kerja yang cukup handal untuk menangani berbagai komputasi analitis dan numeric. Jadi, Maple dapat digunakan dalam perhitungan simbol matematika, perhitungan angka dan membuat grafik matematika.
Software Maple termasuk kategori software komputasi simbolik yang bekerja berdasarkan perintah. Sebagaimana Marjunis (2007: 6) menegaskan "Penulisan, perhitungan, dan manipulasi ekspresi matematis maupun penanganan grafik 2D, 3D dan animasi dapat dilakukan dengan menggunakan perintahperintah dengan sintaks yang mudah serta menampilkan respon solusinya sebagaimana yang diperoleh apabila dikerjakan secara manual".

Maple dapat digunakan sebagai alat bantu untuk mengajarkan konsep aljabar dan kalkulus. Maple sudah dicobakan dalam perkuliahan kalkulus sejak tahun 1988 oleh Robert J Lopez. Lopez (1994) menyatakan "In 1988, with NSF funding under an ILI grant, $i$ had the opportunity to bring Maple into the calculus classroom at Rose-Hulman Institute of Technology. Since then a new curriculum based on the availability of computer algebra systems has evolved at RHIT and in my own courses".

Software maple sudah dikembangkan hingga berbagai versi. Perbedaan antara versi baru dengan versiversi sebelumnya terutama terletak pada fitur-fitur software. Pada penelitian ini, software maple yang digunakan adalah Maple 14.

\section{Materi Kalkulus Dasar dan Lanjut}

Suherman (2004: 17) menjelaskan "Pada permulaannya cabang-cabang matematika yang ditemukan adalah Aritmatika atau Berhitung, Aljabar dan Geometri". Setelah itu ditemukan Kalkulus yang berfungsi sebagai tonggak penopang terbentuknya cabang matematika baru yang lebih kompleks, antara lain Statistika, Topologi, Aljabar (Linear, Abstrak, Himpunan), Geometri (Sistem Geometri, Geometri Linear), Analisis Vektor, dan lain-lain.

Secara gMarjunis besar materi matematika dapat dikelompokkan menjadi 5 bagian yaitu: Kalkulus, Statistik, 
Geometri, Aljabar dan Terapan. Untuk STAIN Batusangkar, materi Kalkulus diberikan selama 3 semester yakni pada semester pertama, kedua dan tiga. Kalkulus dasar untuk semester satu dan dua dengan nama mata kuliah Kalkulus 1 dan 2, sedangkan kalkulus lanjut untuk semester tiga dengan nama mata kuliah Kalkulus Peubah Banyak 1 (KPB 1).

Mata kuliah Kalkulus 1 merupakan mata kuliah wajib yang diberikan pada semester 1 dengan beban 3 SKS. Materi yang diberikan meliputi sistem bilangan riil dan ketaksamaan, fungsi dan grafik, limit dan kekontinuan, turunan dan aplikasinya serta penerapannya dalam berbagai masalah yang berkaitan dengan topik tersebut.

Mata kuliah Kalkulus 2 adalah mata kuliah lanjutan untuk Kalkulus 1 dengan beban 3 SKS. Mata kuliah Kalkulus 2 membahas tentang: integral tak tentu sebagai anti turunan, penerapan integral tak tentu, teorema dasar kalkulus untuk integral dan penerapannya, penggunaan integral tentu, fungsi logaritma, fungsi balikan, fungsi eksponen, fungsi balikan trigonometri, fungsi hiperbola dan balikannya, fungsi substitusi peubah baru, pengintegralan parsial, pengintegralan fungsi rasional, pengintegralan dengan substitusi fungsi trigonometri, teorema L'Hopital dan bentuk tak tentu integral tak wajar.

Mata kuliah KPB1 juga diberikan dengan beban 3 SKS. Materi KPB 1 meliputi sistem koordinat kutub, geometri di ruang tiga, turunan dalam ruang dimensi $\mathrm{n}$ dan integral dalam ruang dimensi n. Bagian akhir dari kompetensi dasar untuk materi sistem koordinat kutub dan geometri di ruang tiga adalah mahasiswa mampu menggambar grafik dari fungsi yang diberikan.

Materi kalkulus dasar dan lanjut yang dipilih untuk modul Maple adalah fungsi dan limit, turunan dan integral fungsi satu peubah pada sistem koordinat Cartesius, grafik fungsi pada sistem koordinat polar, grafik fungsi dua peubah pada sistem koordinat Cartesius dan kurva ketinggian.

\section{METODE PENELITIAN}

Penelitian ini dilaksanakan dengan menggunakan pendekatan penelitian pengembangan (development research). Menurut Soenarto (2005: 1), penelitian pengembangan adalah upaya untuk mengembangkan dan menghasilkan suatu produk berupa materi, media, alat, atau strategi pembelajaran, digunakan untuk mengatasi masalah pembelajaran di kelas/laboratorium, dan bukan untuk menguji teori. Akker \& Plomp (1994: 462) menjelaskan tujuan penelitian pengembangan sebagai berikut:

1. Better understanding of the implementation problems of the teachers:

2. Development of prototypical project interventions (training, materials, support), including empirical evidence of their quality;

3. Generating methodological directions for the design and evaluation of such products or intervention;

4. Increased (both individual and collective) expertise of the various participant).

\section{HASIL PENELITIAN}

Modul Maple untuk kalkulus dasar dan lanjut dibuat terdiri atas tiga bagian yaitu pendahuluan, kegiatan belajar dan penutup. Pendahuluan memuat petunjuk penggunaan modul, peta konsep materi, deskripsi materi dan learning outcomes. Kegiatan belajar yang dirancang ada sebanyak 7 kegiatan yaitu mengenal Maple 14, fungsi dan limit, turunan, integral, grafik persamaan kutub, grafik di ruang dimensi tiga, dan kurva ketinggian. Setiap kegiatan berisi tujuan 
pembelajaran, materi pokok, uraian materi, latihan, rangkuman, tes mandiri dan indikator keberhasilan. Penutup hanya memuat glossary, sumber bacaan dan kunci jawaban tes mandiri.

Berikut gambaran isi dan tampilan masing-masing bagian modul Maple untuk kalkulus dasar dan lanjut yang telah dirancang.

1. Modul dirancang semarik mungkin dengan menggunakan microsoft word 2007 dengan dua jenis huruf yaitu Berlin Sans FB Demidengan ukuran
14 dan Lucida Bright dengan ukuran 12.

2. Cover didisain dengan menggunakan corel draw. Cover depan memuat judul modul, tujuan modul, ilustrasi isi modul berupa grafik di ruang tiga dan logo software Maple, nama penulis dan instansi penulis. Cover belakang memuat biodata penulis. Cover yang telah dirancang dapat dilihat pada Gambar 1 .

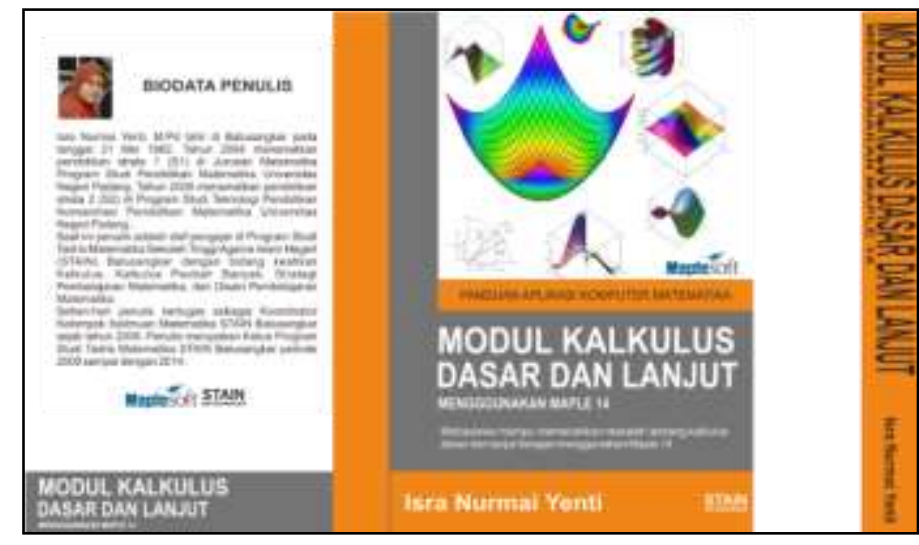

Gambar 1. Cover Modul

3. Modul memuat kata pengantar yang menggambarkan alasan pembuatan modul dan isi modul. Kata pengantar yang dibuat tampak pada Gambar 2 .

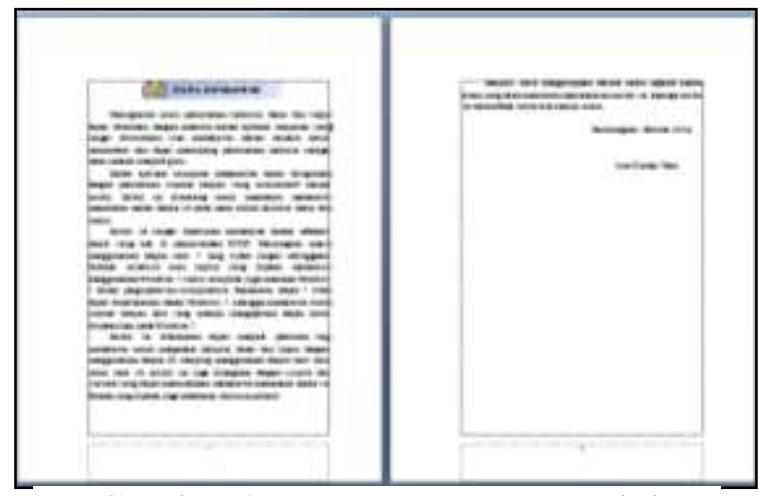

Gambar 2. Kata Pengantar Modul

4. Modul memiliki daftar isi yang bertujuan agar mahasiswa mudah menemukan bagian yang akan dicari dan dipelajari. Contoh daftar isi modul terlihat pada Gambar 3. 


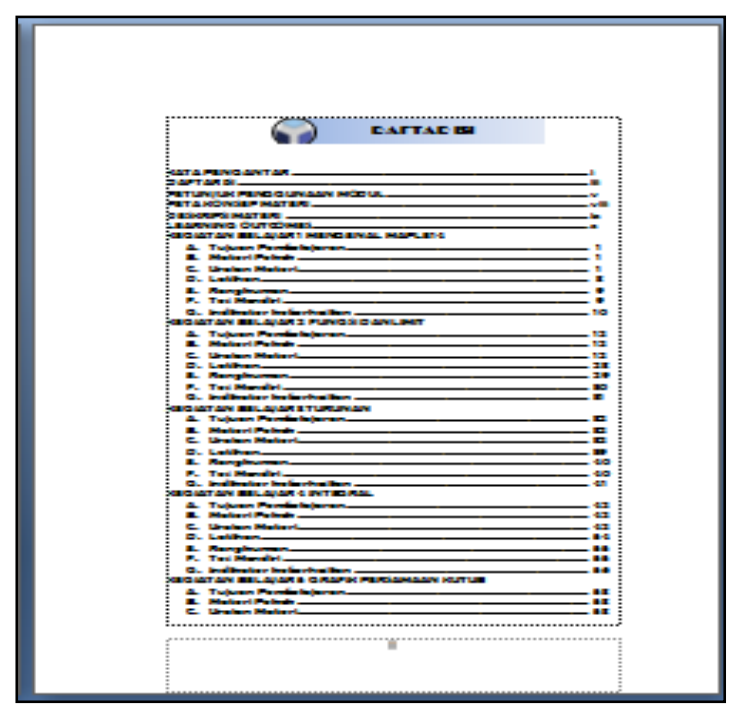

Gambar 3. Daftar Isi Modul

5. Pada bagian pendahuluan dari modul terdapat petunjuk penggunaan modul. Petunjuk ini terdiri atas 2 macam yaitu petunjuk isi modul yang berisi gambaran setiap komponen dari modul dan petunjuk bagi mahasiswa tentang cara mempelajari modul ini. Contoh tampilan petunjuk penggunaan modul disajikan dalam Gambar 4.

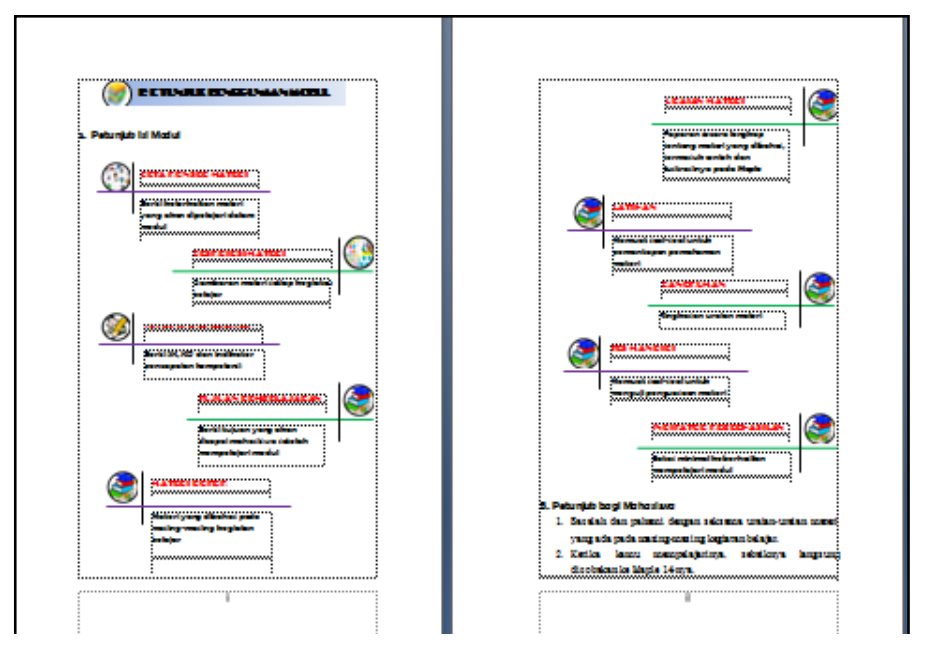

Gambar 4. Petunjuk Penggunaan Modul

6. Modul ini juga memiliki peta konsep materi di bagian pendahuluannya. Peta konsep ini berfungsi mengaitkan materi kalkulus dasar dan lanjut yang dapat digunakan dalam Maple 14. Hasil rancangan peta konsep materi tampak pada Gambar 5. 


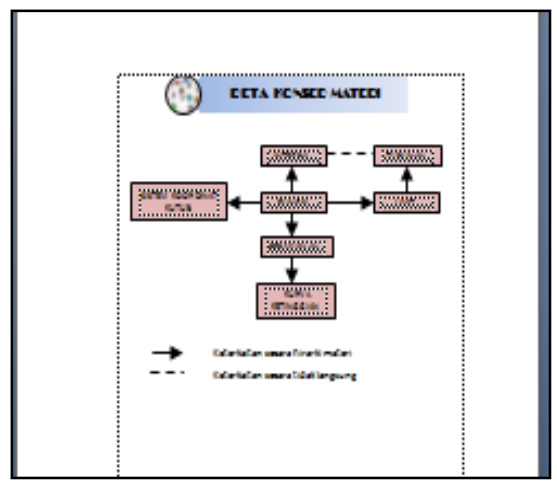

Gambar 5. Peta Konsep

Materi Modul

7. Setiap materi kegiatan belajar terdapat di bagian awal modul. Hasil dipaparkan dalam deskripsi materi yang rancangannya ada pada Gambar 6.

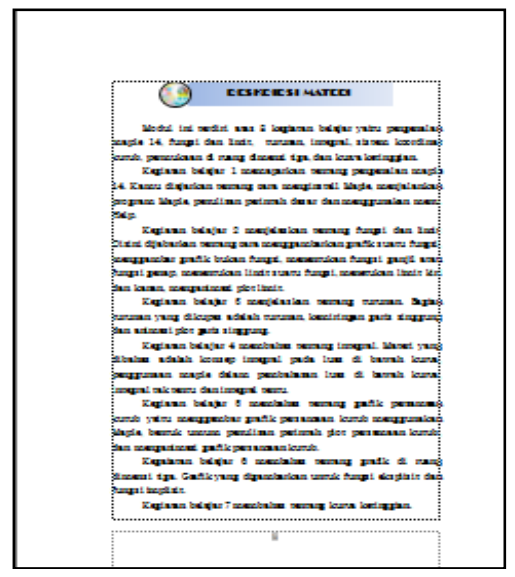

Gambar 6. Deskripsi Materi Modul

8. Gambaran Standar Kompetensi, Kompetensi Dasar dan Indikator Pencapaian Kompetensi terdapat pada Learning Outcomes di bagian pendahuluan. Contoh hasil disain learning outcomes dapat dilihat pada Gambar 7. 


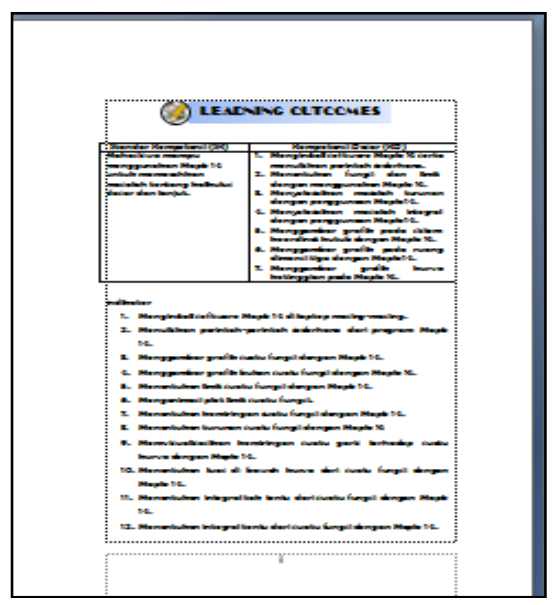

Gambar 7. Learning Outcomes Modul

9. Setiap judul kegiatan belajar dipakai adalah Broadway dengan dirancang dengan menggunakan SmartArt Graphic. Huruf yang ukuran 15. Hasil disainnya tampak pada Gambar 8.

\section{KEGIATAN BELAJAR I, MENGENAI MADIE 14}

Gambar 8. Judul Kegiatan Belajar pada Modul

10. Setiap kegiatan belajar memuat tujuan pembelajaran, materi pokok, uraian materi, latihan, rangkuman, tes mandiri dan indikator keber-

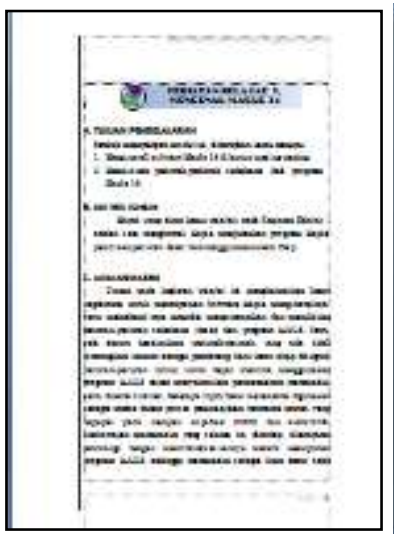

Gambar 9. Tujuan Pembelajaran, Materi Pokok dan Uraian Materi pada Modul hasilan. Contoh isi dan tampilan masing-masing bagian dapat dilihat pada Gambar 9 dan Gambar 10.

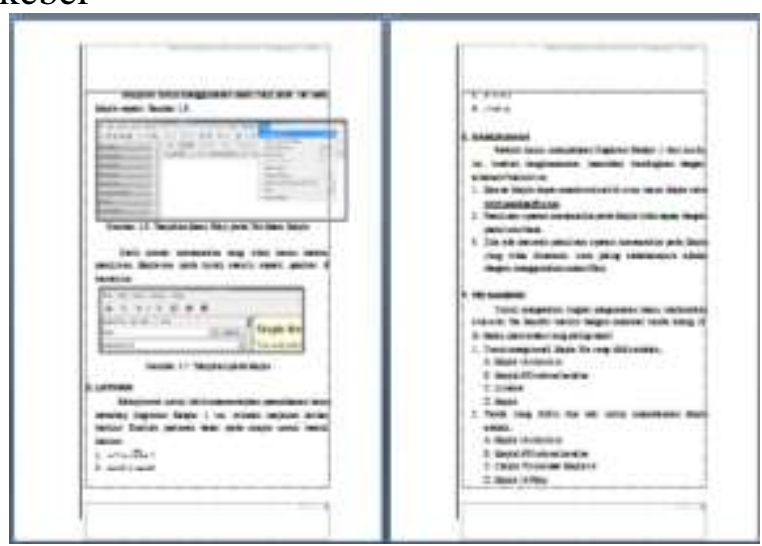

Gambar 10. Latihan, Rangkuman dan Tes Mandiri pada Modul 
11. Modul ini memiliki daftar istilah penting yang terletak pada bagian dimasukkan ke dalam Glossary. penutup. Daftar istilah penting Contoh disain Glossary dapat dilihat pada Gambar 11.

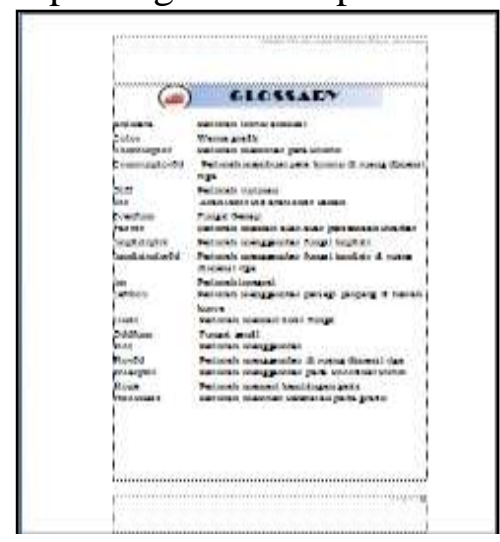

Gambar 11. Glossary Modul

12. Sumber isi modul diambil dari beberapa buku yang dapat dilihat pada Sumber Bacaan. Hasil

rancangan Sumber Bacaan tampak pada Gambar 12.

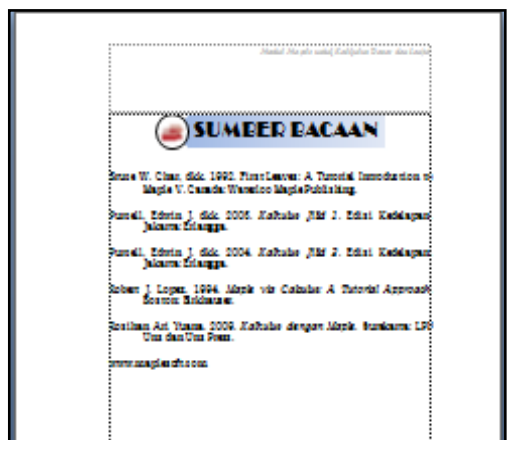

Gambar 12. Sumber Bacaan dari Modul

13. Bagian akhir dari modul ini dilengkapi dengan kunci jawaban tes mandiri. Hasil disainnya dapat dilihat pada Gambar 13.

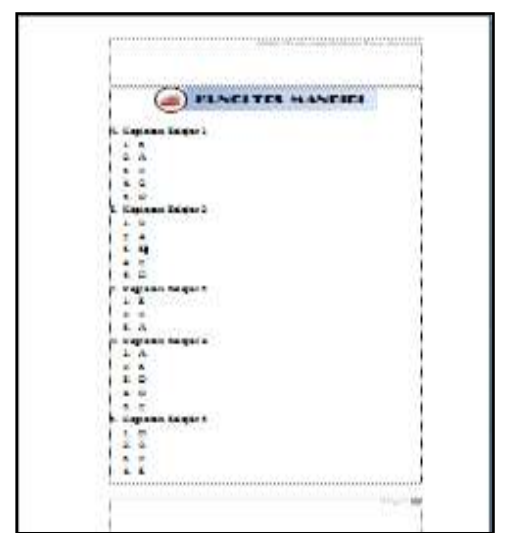

Gambar 13. Kunci Jawaban Tes Mandiri Modul 


\section{PEMBAHASAN}

Modul dirancang berdasarkan modifikasi format modul menurut Rahman, karena ada beberapa perubahan yang dilakukan berdasarkan hasil analisis muka belakang. Hal ini sesuai dengan pendapat Daryanto (2013: 11) yaitu modul harus dikembangkan atas dasar hasil analisis kebutuhan dan kondisi.

Berdasarkan format tersebut, disusun modul untuk masing-masing bagiannya. Agar menghasilkan modul pembelajaran yang bagus dan menarik, modul perlu dirancang dan dikembangkan dengan memperhatikan format, organisasi, daya tarik, ukuran huruf, spasi kosong dan konsistensi yang diungkapkan oleh Daryanto (2013:1315) sebagai berikut:

1. Format

a. Gunakan format kolom (tunggal atau multi) yang proporsional. Penggunaan kolom tunggal atau multi harus sesuai dengan bentuk dan ukuran kertas yang digunakan. Jika menggunakan kolom multi, hendaknya jarak dan perbandingan antar kolom secara proporsional.

b. Gunakan format kertas (vertikal atau horizontal) yang tepat. Penggunaan format kertas secara vertikal atau horizontal harus memperhatikan tata letak dan format pengetikan.

c. Gunakan tanda-tanda (icon) yang mudah ditangkap dan bertujuan untuk menekankan pada hal-hal yang dianggap penting atau khusus. Tanda dapat berupa gambar, cetak tebal, cetak miring atau lainnya.

2. Organisasi

a. Tampilkan bagan/peta yang menggambarkan cakupan materi yang akan dibahas dalam modul.

b. Organisasikan isi materi pembelajaran dengan urutan dan susunan yang sistematis, sehingga memudahkan peserta didik memahami materi pelajaran.

c. Susun dan tempatkan naskah, gambar dan ilustrasi sedemikian rupa sehingga informasi mudah dimengerti oleh peserta didik.

d. Organisasikan antar bab, antar unit dan antar paragraf dengan susunan dan alur yang memudahkan peserta didik memahaminya.

e. Organisasikan antar judul, subjudul dan uraian yang mudah diikuti oleh peserta didik.

3. Daya tarik

a. Bagian sampul (cover) depan, dengan mengkombinasikan warna, gambar (ilustrasi), bentuk dan ukuran huruf yang serasi.

b. Bagian isi modul dengan menempatkan rangsangan-rangsangan berupa gambar atau ilustrasi, pencetakan huruf tebal, miring, gMarjunis bawah atau warna.

c. Tugas dan latihan dikemas sedemikian rupa sehingga menarik.

4. Bentuk dan ukuran huruf

a. Gunakan bentuk dan ukuran huruf yang mudah dibaca sesuai dengan karakteristik umum peserta didik.

b. Gunakan perbandingan huruf yang proporsional antar judul, sub judul dan isi naskah.

c. Hindari penggunaan huruf kapital pada seluruh teks, karena dapat membuat proses membaca menjadi sulit.

5. Ruang (spasi kosong)

Gunakan spasi atau ruang kosong tanpa naskah atau gambar untuk menambah kontras penampilan modul. Spasi kosong dapat berfungsi untuk menambahkan catatan penting dan memberikan kesempatan jeda kepada peserta didik. Gunakan dan tempatkan spasi tersebut secara proporsional. Penempatan beberapa ruang kosong dilakukan di beberapa tempat seperti: 
a. Ruangan sekitar judul bab dan subbab.

b. Batas tepi (margin); batas tepi yang luas memaksa perhatian peserta didik untuk masuk ke tengah-tengah halaman.

c. Spasi antar kolom; semakin lebar kolomnya semakin luas spasi diantaranya.

d. Pergantian antar paragraf dimulai dengan huruf kapital.

e. Pergantian antar bab atau bagian.

6. Konsistensi

a. Gunakan bentuk dan ukuran huruf secara konsiten dari halaman ke halaman. Usahakan agar tidak menggabungkan beberapa cetakan dengan bentuk dan ukuran huruf yang terlalu banyak variasi.

\section{DAFTAR RUJUKAN}

Akker, Jan Van Den dan Plomp, Tjeerd. 1994. Educational Development in Developing Countries. Dalam Skutsch, Margaret M., Opdam, J. Hans M. and Nordholt, Nico G. Schulte (Eds.), Towards Sustainable Development. Enschede: Technology and Development Group University of Twente.

Char,Bruce W., dkk. 1992. First Leaves: A Tutorial Introduction to Maple $V$. Canada: Waterloo Maple Publishing.

Daryanto. 2013. Menyusun Modul: Bahan Ajar untuk Persiapan Guru dalam Mengajar. Yogyakarta: Gava Media.

Lopez, Robert J. 1994. Maple via Calculus: a Tutorial Approach. Boston: Birkhauser.

Majid, Abdul. 2006. Perencanaan Pembelajaran: Mengembangkan b. Gunakan jarak spasi konsisten. Jarak antar judul dengan bMarjunis pertama, antara judul dengan teks utama. Jarak bMarjunis atau spasi yang tidak sama sering dianggap buruk, tidak rapi.

c. Gunakan tata letak pengetikan yang konsisten, baik pola pengetikan maupun margin/batasbatas pengetikan.

\section{PENUTUP}

Penelitian ini telah menghasilkan sebuah modul kalkulus dasar dan lanjut dengan menggunakan Maple 14. Modulini dapat dijadikan sebagai panduan belajar Maple 14 pada mata kuliah Aplikasi Komputer Matematika.

Standar Kompetensi Guru. Bandung: Remaja Rosdakarya.

Marjunis, Aris. 2007. Media Pembelajaran Matematika dengan Maplet. Yogyakarta: Graha Ilmu.

Prastowo, Andi. 2012. Panduan Kreatif Membuat Bahan Ajar Inovatif. Yogyakarta: Diva Press.

Rahman, Muhammad dan Amri, Sofan. 2013. Sistem dan Desain Pengembangan Sistem Pembelajaran. Jakarta: Prestasi Pustakaraya.

Soenarto. 2005. "Metodologi Penelitian Pengembangan untuk Peningkatan Kualitas Pembelajaran”. Makalah disampaikan pada Pelatihan Nasional Penelitian Peningkatan Kualitas Pembelajaran dan Penelitian Tindakan Kelas (PPKP dan PTK) bagi dosen LPTK, Denpasar dan Batam. 
Suherman,Erman. dkk. 2004. Common TextBook Strategi Pembelajaran Matematika Kontemporer. Bandung: JICA-Universitas Pendidikan Indonesia (UPI).

Yenti, Isra Nurmai. 2010. "Pengembangan Bahan Ajar Berbasis E-
Learning untuk Mata Kuliah Kalkulus Peubah Banyak 1 (KPB 1) di STAIN Batusangkar". Laporan Penelitian tidak diterbitkan. Batusangkar: STAIN Batusangkar. 